\title{
Tech Mining to Generate Indicators of Future National Technological Competitiveness: Nano-enhanced Drug Delivery (NEDD) in the US and China
}

\author{
Ying Guo, ${ }^{1}$ Xiao Zhou, ${ }^{2}$ Alan L. Porter ${ }^{3}$ and Douglas K.R. Robinson ${ }^{4}$ \\ ${ }^{1}$ guoying_bit@163.com
}

School of Management and Economics, Beijing Institute of Technology, Beijing (China)

${ }^{2}$ belinda1214@126.com

School of Management and Economics, Beijing Institute of Technology, Beijing (China)

3alan.porter@isye.gatech.edu

School of Public Policy, Georgia Institute of Technology, Atlanta (USA), and Search

Technology, Inc., Norcross, GA (USA)

${ }^{4}$ douglas.robinson@teqnode.com

TEQNODE Limited, Paris (France)

$\&$

IFRIS-LATTS, Université de Paris-Est (France)

\begin{abstract}
"Global technological competitiveness" is widely acknowledged, but the challenge is to go beyond this recognition to develop empirical indicators of important transitions. These may concern particular technologies, the competitive position of particular organizations, or national/regional shifts. For decades, the US has been the world leader in biomedical technologies, with attendant implications for organizational priorities in terms of $R \& D$ location and market targeting. Recent years have seen a tremendous acceleration in Asian research in most domains, including biomedical, particularly visible in China. This paper investigates comparative patterns between the US and China in a promising emerging area of biotechnology -- Nano-Enabled Drug Delivery. It then explores indicators of, and implications for, future transitions at the national level - an approach we label "Forecasting Innovation Pathways.”
\end{abstract}




\section{KEYWORDS}

Tech mining; Nano-Enabled Drug Delivery; Comparative patterns; Innovation pathways

\section{Introduction}

Nano-enhanced Drug Delivery (NEDD) systems seek to improve the release, distribution, absorption, and elimination of drugs. Traditional methods for administering drugs have relied on absorption in the digestive tract or skin or on injection (with manifold issues). We investigate new delivery methods that use nanoparticles (e.g., lipid-based, polymer-based, proteins, dendrimers, etc.) to target specific organs or cell-types [1]. These may increase drug effectiveness, both via "technical" and "social" effects - e.g., by controlling release one can reduce the size of dose and frequency and improve patient compliance. NEDD offers potential for treating chronic diseases and genetic disorders, and it has also been considered as a suitable substitute for conventional protein therapy.

China is on the rise in the drug delivery technology sector and is becoming an increasingly nimble competitor in the space. Chinese drug delivery companies are seeking to expand their opportunities into Europe and the US. One company, Lepu Medical Technology, uses its nanomaterial technology to make drug-eluting coronary stents, among other interventional cardiology products, and the company captured $\$ 120$ million in revenue in 2011. Meanwhile, just as for other frontier technologies, the US has been the dominant leader in the area of biotech. Thus, with this context, it is important to underscore to what extent these two countries are progressing in this frontier technology -- NEDD.

This NEDD study is part of a project seeking to develop methods to Forecast Innovation Pathways (FIP) for "New and Emerging Science \& Technologies" (NESTs) [2]. NESTs have great potential for innovation, but at the same time they are associated with great uncertainties. The nurturing of appropriate research avenues is crucial so that NESTs are developed along the most promising pathways, both in technological terms as well as towards 
addressing societal and economic problems or needs.

The project aims to develop a methodological framework and associated tools for analyzing NESTs to help policy makers and R\&D managers to make better-informed decisions regarding innovation pathways. It combines empirical and expert knowledge of an emerging technology. The empirical work mainly seeks to extract intelligence from database search results about R\&D activities, technological maturation, key players, and promising prospects for applications. This reflects a combination of bibliometrics and text mining (i.e., "Tech Mining" [3,4]). The case studies in the project (one is NEDD) are to be followed by expert interviews, and a dedicated workshop with stakeholders to explore innovation pathways (planned for March, 2014).

The development of new profiling and mapping techniques to characterize key actors and their interactions is crucial. Our hypothesis supposes that by understanding the various bodies of knowledge involved in a NEST, the key organizations, how they are related, and the visions they have constructed, analysts can grasp the diverse potential innovation pathways. Our approach aims to support the identification of previously hidden possibilities for connections among new ideas, artifacts and actors relating to NEDD [5] - hence trying to preserve diversity in order to avoid technological lock-in towards undesired applications [6].

The content for this paper can be divided into four parts. After this general introduction we follow with a description of the Contextual Framework and Research Approach. The third section presents the results of the bibliometric analysis. The last section sums up and points out promising "next" research opportunities to pursue.

\section{Contextual Framework \& Research Approach}

\subsection{Data \& Search strategy}

We started researching NEDD in 2008. After multiple trials and iterations to enhance our 
search strategy, we have developed a multi-module approach to construct an NEDD dataset from Web of Science (WOS), using the Georgia Tech (GT) "nano" (nanoscience, nanoengineering, nanotechnology, etc.) dataset [7] with additional searches in the full WOS. We assessed an extensive range of candidate search terms, drawn from an earlier study, a doctoral dissertation investigation, a literature review (especially of review and foresight articles about NEDD), and expert opinions. We grouped those terms into seven categories. After further testing and comparison, plus another round of expert review, we set aside three categories ("B" - biological processes; "I" - imaging; and "H" - helpers). We largely set aside "T" (targeting) terms as well. In so doing, we note that their inclusion would greatly expand the dataset, but at the expense of increased search complexity and a greater degree of opacity in terms of what is included, and the resultant NEDD set would be biased in favor of those particular terms. For the base NEDD search, we focused mainly on three categories: P (Pharmaceutical), N (Nano), and D (Delivery), with limited incorporation of "T" terminology. Our colleague Xiao Zhou leads the search strategy analysis and presents the process in detail [8]. The WOS record set generated for 2000-2012 includes 61,465 abstract records in December 2012.

Table 1 Nano-enabled Drug Delivery: related terms

\subsection{Framework \& Research questions}

New and Emerging Science \& Technologies (NESTs) have some obvious characteristics. First, plenty of scientists believe in the future of any given NEST and apply themselves to advance it; so such technologies often show accelerating $R \& D$ activity and rapid development. Second, NEST R\&D is often multidisciplinary or interdisciplinary, as is the case for nano science and engineering [9]. Third, because of the first two characteristics, 
NEST often calls for cooperative development, which could be among different researchers, institutions, or countries. When we explore the R\&D activity for a given NEST, we address these three characteristics as indicators. In this paper, we apply them to NEDD.

As noted, our analyses of NEDD research activity presented in this paper focuses on China and the US. In general, we would like to know to what extent these two countries have developed competency in this high technology area. Is this technology providing a "window of opportunity" for these two countries to compete in the near future? Considering the three characteristics of NESTs mentioned, the study investigates in detail to what extent China and the US are asserting themselves to possibly establish dominance over NEDD applications to come. Specific questions that drive this paper are as follows:

- Research activity trend analysis (Rapid development): Does rapidly increasing publication activity portend "commercial" development?

- Research concentration difference analysis (Cross-disciplinary): How scattered and different are Chinese and American NEDD research concentrations? This could help researchers locate and balance their research emphases.

- Research cooperation network analysis (Collaboration patterns): What does the network within and among these key countries look like? To follow up, can we analyze and visualize the networks within countries to reveal different $R \& D$ mechanisms at work (and possibly suggest policy initiatives)?

The study also intends to demonstrate the importance of integrating bibliometrics and text analyses to generate informative innovation indicators, helping to construct a more informed picture of a country's likely future performance. 


\section{Results for China and US NEDD Research Performance}

\subsection{Research activity trend analysis}

Because WOS indexing of some 12,000 journals' content is done with some time lag, the data for 2011 and 2012 are incomplete. For trend analyses, we want to estimate the full activity for those years. We used total annual publication counts in recent years in WOS, expressly for its Science Citation Index (SCI) to normalize the NEDD data. We multiplied these ratios of expected/observed values to adjust the observed NEDD counts for these two years for each country to compare the research activity trend for China and the US.

Figure 1 compares the ten leading countries in NEDD research to provide perspective on the degree to which the US and China dominate. As noted, in 2001 and thereabouts, US domination was particularly striking. For China, a steady rise in publication output has been observable, particularly since 2006. Taking 2001 as the base year, China's relative growth rate has been much higher than that of the US. In 2001, the US accounted for $45.5 \%$ of the NEDD papers, whereas Germany accounted for $10.4 \%$ of papers, and China for $2.5 \%$. In 2011, China accounted for $23.5 \%$ of papers and US researchers authored or co-authored $26.2 \%$, whereas Germany was considerably less visible, accounting for $5.8 \%$ of total papers. Overall, for the aggregate publications from 2001 to 2012, China accounts for 10,110 NEDD papers ( $16.45 \%$ of the global total); the US, for 20,807 papers $(33.85 \%$ of the total).

Figure 1 Activity Trends for the Top 10 NEDD Countries

We then explored several growth models for their fit to the historical data (2000-2012) for both countries (Figure 2). We ran these for the annual counts and for cumulative totals which shows clearly a strong growth in NEDD research. Fisher-Pry (logistic, S-curve) fits 
with alternative posited upper limits show excellent fits to the data ${ }^{1}$. With an interest in projecting a couple of years ahead, growth seems reasonable. (Longer term, near-exponential growth in the number of NEDD research publications would not be sustainable.) Our data reveals different patterns for the US and China. US would point to 4,600 or so publications in 2014 (up from an estimated 3,600 in 2012). China would project to about 7,600 in 2014 $(\mathrm{R} 2=0.99)$. This S-curve would indicate that China's annual publication rates will much higher than US in the next couple years.

Figure 2 US (left)/ China(right) Cumulative Trend for NEDD-related Publications in WOS

Before hailing the rapid increase in the number of publications in China, one should bear in mind that knowledge production has been growing exponentially in numerous countries and disciplines. China's astonishing publication activity is particularly reflected in the whole emerging field of nanotechnology. Measured by the number of nano research articles, previous studies have consistently shown that China is now the world's second largest producer in this nascent domain $[10,11,12,13]$.

Citation Analyses: Citation measures provide a view of the reception of papers by the international community [14]. However, any indicator based on citations received is strongly affected by the citation window. The larger volume of US papers until recently leads to more citations than for China. The difference becomes less significant when this is normalized by number of papers and the number of years in which the paper could receive cites. We create Figure 3 to compare the citations/paper/year and the rate of uncited papers with the trend of total papers for both the US and China. Columns in the Figure 3 represent citations/paper/year for both countries and are indicated on the left $\mathrm{Y}$ axis; the line chart represents the number of uncited papers/total for each year for both countries and is charted

\footnotetext{
${ }^{1}$ The dominant form of fitting growth models is the logistic, and Fisher-Pry is a prominent version of that [4].
} 
on the right $\mathrm{Y}$ axis.

Interestingly, we do not observe much difference in the corpus of papers that remain uncited, except for the year 2005. Considering the citations/paper/year, one important indication is how fast the papers of both countries are received by the international community. Except for 2011 and 2012, citation for the US obviously progresses steadily, while for China, it looks erratic but possibly rising. Most tellingly, while China's citation rate lags behind that of the US, the gap seems to moderate in recent years. These bibliometric indicators imply that China's research is addressing important problems, advancing knowledge, and making researchers take note of that (Figure 3).

Figure 3 Citation trends for the US and China

An examination of the 100 most cited papers sheds further light on research impact. These papers may offer significant theoretical and/or experimental novelty to draw the attention of the research community. For this analysis, we fully credit a country for any paper on which it appears in one or more of the co-authors' addresses.

The most cited papers present a rather different picture than average citation rates (we don't show the map here). We see only 2 Chinese papers among those top 100 highly cited papers, while 62 belong to the US. Also, interestingly, some countries appear with significant frequency in the 100 most cited papers - e.g. the Netherlands with 10 such papers (ranking 4th) - but are absent in the top 10 highly active countries (Figure 1). This possibly means that the Netherlands NEDD community pays more attention to quality than quantity of research.

We generate a map for the Top 20 affiliated organizations based on how similarly they cite the top 200 reference papers in the dataset, and we also mark the boxplot for citation analysis for some US and China affiliations (Figure 4). From this map, we can see several key points: 
1) Most affiliations in the top 20 list come from the US or China, which is not surprising as they are the top 2 countries for NEDD research activity.

2) China's research affiliations have much more common focus than those in of the United States. All of the Chinese affiliations are linked together by how much they cite the same references (top-left part of this map).

3) The most cited paper comes from the University of Washington (US) -- cited 4005 times, while for China, the highest one is from the University of Shanghai Jiaotong -with 816 . This again suggests a quality gap between the US and China.

4) From examination of the distributions of times cited (Boxplots), we see the gap again. For China, in those affiliations, the best $75 \%$ quartile is 10 , while the worst is 8 . These two number are much higher for US, which are 39 and 24.5 separately.

Figure 4 Top 20 affiliations (cross-correlation map based on top 200 cited reference)

\subsection{Hot Topics and Research Concentration Difference Analyses}

We scanned for hot topics within this area for both countries - i.e., topics within the domain that evidence increasing research attention in recent years. After identifying hot topics by comparing the prevalence of key terms in a very recent period (here we use 2011-on) vs. an earlier period (here, 2000-2010), we examined 424 interesting, frequently occurring key terms in both periods. Table 2 lists the 20 topics that show the greatest increase in attention these past two years. Overall, the ratio of 2011 -on to pre-2011 is 0.43 . We can conclude thatthese terms are very "hot." For both countries, nano-related terms are hot, especially for the US. Also, we highlight 3 terms that appear in both lists, for China and the US. This illustrates the potential to identify respective research concentrations (to be probed further in 
consultation with several domain experts).

Table 2 Increasingly Popular NEDD Research Topics for US and China

In our exploration of NEED, Principal Components Analysis [PCA - as provided in VantagePoint text analysis suite of tools (www.theVantagePoint.com) $\left.{ }^{2}\right]$ was applied to the most interesting (about 424) clumped term set [8] to cluster these as potentially important factors for sub-systems and research concentration analyses for China and the US. We created a sub-dataset with US and China records, then made the factor map in Figure 5. Each node may represent several descriptors that are combined based on how frequently they occur together. Proximity and links show higher correlation among terms.

We added the "country" field to each node to look for any big research concentration difference between the US and China. As we have noted earlier, we fully credit a country for any paper on which it appears in one or more of the co-authors' addresses. So, perhaps more than one country could apply to an individual paper. In this analysis, for those papers with international cooperation, they have a second country attributedbesides US or China. As for overall level, China accounts for 10,110 NEDD papers (16.45\% of the global total); the US, for 20,807 papers ( $33.85 \%$ of the total). The US publication number is almost double that of China. We have not shown the pull-down box for topical concentrations with similar ratios, but show those with interesting differences (Figure 5).

Looking at cardiomyopathy, retroviral vectors, viral vectors, NF-KAPPA-B, DNA vaccine, and malignant glioma, China lags behind in terms of publications, especially for retroviral vectors and viral vectors. Such a big difference is surprising: viral or retroviral vectors are widely used in gene therapy, since they can directly deliver genetic material into

\footnotetext{
${ }^{2}$ Beyond one-dimensional (Lists) and two-dimensional (Matrices) analyses, VantagePoint performs multidimensional statistical analysis to identify clusters and relationships among concepts, people, organizations, and countries.
} 
cells. Nanosuspensions, $\mathrm{N}$-isopropylacrylamide and solid lipid nanoparticles are related to easy delivery for certain drugs, using nano-size properties. China could compete with the US on number of publications.

Figure 5 Factor map for US and China records

NEDD is highly interdisciplinary, emerging out of a strong intersection of different disciplines. For a country to create competency in NEDD research is to an extent contingent upon its overall research activity in different disciplines of natural and engineering sciences and to have developed strong cross-disciplinary collaboration. Ideally, a country's research strength should find special reflection in areas vital to NEDD. We examine to what extent research activity of both these countries matches with their publication concentrations.

We made tables of Web of Science Categories (WOSC) and Cited WOSCs for the US and China (Table 3). We also calculated the ratio of number of US/number of China for the items. As the US publication number is almost double that of China, we highlight the ratio numbers with big differences. For cited WOSCs, the ratio is balanced, only 2 higher than 3 , highlighted in the table. However, for publication concentrations, there are big differences among them. It's interesting to see that they generally cite similar papers, but publish in different areas. For Biotechnology \& Applied Microbiology; Medicine, Research \& Experimental; Genetics \& Heredity; Virology; and Biochemical Research Methods, the ratio is much higher than 2. But, for Polymer Science and Materials Science, and Biomaterials, China publishes a notable number of papers.

Table 3 Top WOSC and Cited WOSCs for the US and China

Elsewhere in this paper we investigated topics at two levels - WOSCs (224 categories) and top topical terms (424). Here we take a more aggregate perspective, looking at the 19 
Macro-Disciplines (MDs) that consolidate the WOSCs based on their relations to each other (based on all 2010 WoS cross-citations). NEDD research indexed in WoS emphasizes 2 of the 19 MDs: $54 \%$ of the 61,465 NEDD papers address Biomedical Science and $42 \%$ tap Materials Science (based on the journals in which published, and some $40 \%$ of journals are associated with multiple WOSCs) - so obviously many NEDD papers combine both broad interests. Not surprisingly, each of the target 35 research organizations addresses both, but emphases vary. This might suggest complementary interests, with collaboration potential e.g., Georgia Tech's ratio of Materials Science to Biomedical Science is 2.0 while the University of Alabama is 0.2 .

As our research moves forward, we plan to focus on sub-areas within NEDD. For now, we note how these multi-tier topical representations (MDs, WOSCs, 424 key terms, and 21 factors based on the key terms) can help identify research "hot spots." To illustrate, one factor (composed of topics that tend to co-occur in records) concerns "retroviral vectors." We can open a detail window in VantagePoint to show that among the 25 top US research organizations, 10 have 10-28 articles relating to these vectors - i.e., widespread interest. In China, however, only Shanghai Jiao Tong University and the Chinese Academy of Sciences (CAS) have more than 3 articles, so expertise appears much more concentrated.

When we seek topical expertise, such analyses will help us locate research groups and individuals. For instance, a quick scan finds K.V Morris, UCSD, as having first-authored the most papers relating to retroviral vectors. A good follow-up to enrich these database mining efforts is the internet. Pursuing this illustration, Google Scholar identifies a paper by Kevin V. Morris in Science in 2004 on "Small interfering RNA-induced transcriptional gene silencing in human cells" with 678 cites. WoS finds a 2012 paper co-authored by him with a Scripps address and e-mail, which enables us to follow up on this lead (which we intend to do). 


\subsection{Research Collaboration Network Analysis}

Using the Web of Science Categories for the US and China, we examine what happens for international collaboration. We use the "number of countries" field to analysis how much international collaboration there is for the US and China (represented by "US-IC (International Collaboration)" and "China- IC" in Table 4). For example, for NEDD papers indexed as Biochemical Research Methods by WOS, 22\% of the US papers are co-authored with at least one other country, while $35 \%$ of China's papers are. As the US publication number is almost double that of China, we highlight the ratio numbers with big differences. It is interesting to see that the proportion with international cooperation for each country in particular WOS categories tends to be the inverse of the country's concentration. For example, for Genetics \& Heredity, China lags the US with regards to the number of publications, but international cooperation for China in this WOS category is much higher than in others. It possibly means that international cooperation may help explore opportunities in areas in which one's country does not concentrate so highly.

Table 4 International Cooperation for the Top 20 Web of Science Categories for US and China

NEDD research is widely dispersed across different journals due to its interdisciplinary nature. More details of the activities of the two countries are highlighted in Table 5. This indicates some important aspects of these two countries" publication in journals with "Top 10" records in this field. Table 5 also reflects that international collaboration plays an important role in getting papers published in these journals, especially for J. Virol and Mol. Ther, for China. China shows a striking level of international collaboration for those journals. This analysis could also be conducted on the journals with a high impact factor, which could possibly indicate the publication quality for each country. 
For competitive technical intelligence, vital to R\&D management, we explore the topical emphases of leading research organizations further. For this, we examine the top 54 organizations with 250 or more WoS papers in our NEDD set, tagging 35, in China (10) and the US (25). We then further clean the affiliations field to find possible additional papers with organizational name variations that belong to those 35 (mainly universities). These provide an interesting first-cut at the leading NEDD fundamental research institutions in the two leading countries. Understanding a bit about their emphases (similar or not?) and interconnections offers a reasonable base of knowledge upon which to extend (later).

Simple maps of high frequency co-authoring within the country groups (Figure 6a/b) show modest connectivity within the US, with some obvious geographical affinities (e.g., Georgia Tech with Emory - both in Atlanta). Somewhat surprising, NCI (National Cancer Institute, of the US National Institutes of Health) is only highly connected with its neighbor, Johns Hopkins University. In contrast, the 10 Chinese organizations are more highly connected, with CAS (Chinese Academy of Science) very central (although not universally, highly connected).

Figure 6a/b. Co-authorship Among the Leading Chinese Research Organizations (Left side) and Among US

Organizations (Right side)

We analyzed the cooperation pattern changes within China (Figure 7). Members change for those two maps -- Jilin University, Soochow University, Southeast University, and Tsinghua University are the new members in the right map not appearing in the left map. In addition 4 affiliations disappear, and they are Chinese Academy of Medical Science, Chinese University of Hong Kong, Fourth Military Medical University, and University of Hong Kong. 
It's interesting to see the two universities from Hong Kong are not in the list of top 20 affiliations in "2011 and on" dataset. Digging deeper into these two universities, we found that in the "pre 2011" dataset, the 75\% quartile in the boxplot for University of Hong Kong was 29 and for Chinese University of Hong Kong is 21, which are much higher than other affiliations in the list, which are usually about 10 . So, again, quality and quantity are not equivalent. Another interesting finding is that although Peking University is not the one with the most publications in both maps, it becomes the center of the cooperation network of China after 2011. So, it is a player to be watched carefully as the field advances - perhaps a 'leading indicator' of expanding Chinese NEDD research emphases.

Figure 7 Top 20 affiliations for China (Left: pre-2011 (5723 records); right: 2011 and on (4387 records))

The prospective patent studies are very valuable. They will provide some indication of how well each country is converting its research output into technology. Here, we tried some patent analysis for NEDD in Derwent data. We want to see the attitudes towards the key organisations in patent collaboration. Table 6 gives the top 15 assignees that possess the most NEDD patents. They can be classified into three types: company, academic or research institute, and government department. First, 8 of the top 15 assignees are from the USA, 2 are from China. Compared with large number in WoS dataset, China here is not notable.

12 of the top 15 assignees are companies, 2 are academic or research institutes, and 1 is a government department. Companies dominate, because companies tend to be more enthusiastic when it comes to applying for patents. With respect to cross-organisational patents, not all of the 12 companies are proactive. "TAKEDA PHARM CO LTD" from Japan, the leading company, which applied for 125 patents in NEDD, only has 13 collaborative patents. "INCYTE GENOMICS INC" has no collaborative patents. However, some companies showed extraordinary enthusiasm. All patents from "STINE SEED FARM INC," 
"BIOWINDOW GENE DEV INC SHANGHAI", and "BODE GENE DEV CO LTD

SHANGHAI" are cross-organisational. A possible explanation is that these companies have long-term stable agreements with some organisations. Also, this fully collaborative relationship may actually indicate a synonym; in other words, the different names might represent one and the same assignee. But here we cannot manually recognize them by Derwent code and fuzzy matching.

\section{Discussion and future prospects}

\subsection{Results and discussion}

Nano-enhanced drug delivery (NEDD) systems seek to improve the release, distribution, absorption, and elimination of drugs. NEDD offers potential for treating chronic diseases and genetic disorders and has also been considered as a suitable substitute for conventional protein therapy. This paper conducts a comparative analysis of China vs. the US - two important players in the NEDD race - both to present results on this promising emerging technology and to consider ways to better perform such analyses.

After multiple iterations, we have developed a multi-module search strategy to construct an NEDD dataset from WOS, using the Georgia Tech (GT) "nano" (nanoscience, nanoengineering, nanotechnology, etc.) dataset with additional searches in the full WOS, led by our colleague, Xiao Zhou. Then we conducted several analyses to address research trends, collaboration pattern differences, and social network analyses concerning three characteristics of NESTs for which we aspire to forecast innovation pathways.

Considering the characteristics of NESTs, the paper investigates in detail to what extent China and the US are asserting themselves to possibly establish dominance over NEDD applications to come. Three specific questions drive this paper:

In the "research activity trend analysis," we have compared both activity and citation 
trends for the US and China. The activity trend has dramatically changed since 2001, as China has advanced notably in NEDD research. We fit a Fisher-Pry growth model to the data, and the result indicate that China's annual publication rates will be much higher than the US in the next couple years. However, China's citation rate lags behind that of the US, but the gap has narrowed in recent years. We then applied "term clumping" 3 steps to clean and consolidate topical content in abstract record text sources. Analyzing the resulting key term set, we list the "hot" research topics for both countries. Using PCA to group key terms, we identify concentration differences for the two nations. The differences concerning viral or retroviral vectors are striking and merit reflection on R\&D strategy. But China could compete with the US in terms of publication intensity for nanosuspensions, $\mathrm{N}$-isopropylacrylamide and solid lipid nanoparticles, with implications for certain applications.

Interestingly, the "research cooperation network analysis" shows that, although the US's international network spreads globally, internal collaboration seems somewhat limited. Also, we tried cooperation network analysis within China, and found several key affiliations and their network changes over time. We also tried network analysis on the patent data, which is important in innovation trends. Compared with the extensive within-country networking seen in NEDD research publication (WoS dataset), Chinese collaboration is not notable in patenting. [Of course, such co-invention is generally far less prevalent than co-authoring research publications.]

In order to better understand the future of NEDD and know the focal differences among countries, we need to look within NEDD. We work on sub-system identification for NEDD [8]. We use term clumping methods to obtain topical factors. We consolidate the fields --

\footnotetext{
3 "Term Clustering Analysis," defined by Trumbach and Payne [15], means to cluster the phrases based on "shared words." The more shared words two phrases have, the more similar they are. In this case, the process of "Term Clustering Analysis" goes as follows: (1) group the phrases with more than 2 shared words; (2) if any phrase is grouped into more than 1 cluster, calculate the similarity between the phrase and the clusters where it was grouped and then place the phrase within the cluster with which it has the highest similarity value; (3) in each cluster, calculate the Prevalence of all phrases and name the cluster as the phrase with the highest Prevalence value.
} 
keywords (author's), keywords plus, and title (Natural Language Processing (NLP)) (Phrases) as one field. The total terms for this step are 207,809 . We then apply "term clumping" steps to clean and consolidate the terms. The number of final terms is 49462 . We select the top 500 terms and then exclude more general terms from them. We use 445 terms to generate a Factor Map via VantagePoint's PCA analysis (not shown here). From this factor (actually PCA) mapping, refined through expert review, 19 topical groups result. According to the relationships among them, three candidate sub-systems emerge.

(1) Carriers for drug delivery. Recently, copolymers have been receiving much attention in drug targeting, especially for dendrimer, micelle, and block co-polymer carrier systems because of their high loading capacity for drugs, as well as their unique disposition characteristics in the body [16]. Solid lipid nanoparticles (SLN) also belong to this sub-system.

(2) Gene delivery and therapy. The general NEDD system contains two main "P" (pharmaceutical) parts: drug delivery and gene delivery. Attention to the gene delivery sub-system is increasing. We categorize "gene groups" such as RNA interference, DNA vaccine, and viral vectors into this sub-system.

(3) Agents for in-vivo imaging. Imaging is one of the important aspects of the entire NEDD domain. It is the visualization of living animals for research purposes such as drug development. Quantum dots and metal nanoparticles are grouped together into this sub-system.

This kind of bibliometric "who, what, where, when?" analyses can be pursued in multiple ways. Very quickly, we note for the "retroviral vector" subset of the NEDD papers (1203 papers in our WoS 2000-2012 dataset):

- Most cited papers - The top 6 are all published in 2000-2003, suggesting this is a well-established research interest; concentrated in the US - with 4 of those 6 papers. 
- Hot topics - Dividing the 1203 retroviral vector papers into two subsets: papers published before Year 2011 (pre-2011) and after Year 2011 (2011-on), we identify 17 key terms of the 424 ones. All these key terms occur in 4 or more of the $70 \%$ papers separately; all of those 17 ones also appeared in the pre-2011 set. This suggests a well-established research area. We could pursue to indicate relative intensities post-to-pre, if desired.

- New topics - Again, examining the 2011-on key terms, we can spot 50 key terms appearing in 2 or more papers in the 2011-on subset, of which only 3 are present in the earlier set (pre-2011). Were we exploring possible new research thrusts, we could check these out (e.g., polyplexes).

\subsection{Future analysis prospects}

Based on the logic and methods in this paper, further bibliometric analysis should be made, zooming into on the sub-system level, to deepen the comparison among countries, especially the US and China, and to see whether there are particular differences in expertise between elements of NEDD sub-systems, which is important in order to observe potential specializations in each country. With such information, one could explore the linkages between NEDD subsystem developments and disease interests of the different countries. For example, is arthritis or certain forms of cancer a more important target for the US or for China? If there are differences, this could trigger a further investigation into understanding national innovation approaches and policy.

Also, the bibliometric analysis can generate informative innovation indicators, helping to construct a more informed picture of a country's performance. It further can help establish analytical steps to nominate and assess future innovation pathways ("FIP") for NEDD applications. That FIP process entails combining empirical findings with review and brainstorming by persons representing multiple stakeholder perspectives [17]. In 2010 we 
presented a 4-stage (10-step) framework, as illustrated for the case of nano-enhanced solar cells [18]. Recently we have deepened the rationale and expanded the case base by comparing FIP use for nano-enabled biosensors and Deep Brain Stimulation [17].

To sum up, such "Tech Mining" generates valuable information from R\&D literature resources. This can place a researcher in position to address a wide array of technology management questions concerning this important biomedical area. It can help set up systems to nominate and assess future innovation pathways ("FIP") for NEDD applications. For the future work, the full FIP process entails combining field-level, empirical findings with qualitative review of the literature and structured brainstorming with persons representing multiple stakeholder perspectives [17]. Since NEDD is known to be heavily involved in medical science, the research team will shortly adapt and apply the search algorithm that resulted from this study to recover research publications from MEDLINE. We will then combine and compare with WOS, expecting about a 50\% increase in R\&D information to use in extended analyses. Next, patenting is vital in pharmaceutical technology management; so the team will transfer and adapt the search logic to retrieve patent records in Derwent Innovation Index (DII). In both MEDLINE and patent Tech Mining, a search can combine term-based methods with classification searching.

Acknowledgements: This research draws on support from the following program: National Science Foundation (NSF) Science of Science Policy Program - "Revealing Innovation Pathways" (Award No. 1064146) to Georgia Tech; NSF support through the Center for Nanotechnology in Society (Arizona State University; Award No. 0531194); MOE (Ministry of Education in China) Project of Humanities and Social Sciences (Award No. 13YJC630042); Excellent Young Scholars Research Fund of Beijing Institute of Technology ( Award No. 2012YR2114). The findings and observations contained in this paper are those 
of the authors and do not necessarily reflect the views of the NSF of US and MOE of China. The earlier version of this paper was presented in 2013' Portland International Conference on Management of Engineering and Technology (PICMET).

\section{References}

[1] Allen, T. M., Cullis, P.R. Drug Delivery Systems: Entering the Mainstream. Science, 303, 1818-1822, 2004

[2] Porter, A.L., Cunningham, S.W., and Sanz, A.. Extending the FIP (Forecasting Innovation Pathways) approach through an automotive case analysis, Portland International Conference on Management and Engineering Technology (PICMET), San Jose, California, 2013.

[3] Cunningham, S.W., Porter, A.L.; Newman, N.C. Tech Mining Special Issue, Technology Forecasting and Social Change, Vol. 73 (8), 2006

[4] Porter, A.L., and Cunningham, S.W. Tech Mining: Exploiting New Technologies for Competitive Advantage. New York: Wiley, 2005.

[5] Rammert, W. The cultural shaping of technologies and the politics of technodiversity. Sorensen, K.H. and Williams, R. (Eds.) Shaping technology, guiding policy: concepts, spaces and tools. Cheltenham, UK: Edward Elgar. 2002

[6] Stirling, A. A general framework for analysing diversity in science, technology and society. Journal of The Royal Society Interface, 4(15), 707-719, 2007.

[7] Arora, S.K., Porter, A.L., Youtie, J., and Shapira, P. Capturing new developments in an emerging technology: An updated search strategy for identifying nanotechnology research outputs, Scientometrics, DOI: $10.1007 / \mathrm{s} 11192-012-0903-6,2013$

[8] Zhou, X., Porter, A.L., Robinson, D.K.R., and Guo, Y. Analyzing Research Publication Patterns to Gauge Future Innovation Pathways for Nano-Enabled Drug Delivery, Portland International Conference on Management and Engineering Technology (PICMET), San Jose, California, 2013.

[9] Porter, A.L., and Youtie, J., "How Interdisciplinary is Nanotechnology? " Journal of Nanoparticle Research, vol. 11(5), 1023-1041, 2009.

[10] Hullmann, A. Measuring and assessing the development of nanotechnology. Scientometrics, 70(3), 739-758, 2007. 
[11] Kostoff, R. N., Koytcheff, R. G., \& Lau, C. G. Y. Global nanotechnology research metrics. Scientometrics, 70(3), 565-601, 2007.

[12] Kostoff, R. N., Koytcheff, R. G., \& Lau, C. G. . Structure of the nanoscience and nanotechnology applications literature. Journal of Technology Transfer(33), 472-484, 2008.

[13] Zhou, P., \& Leydesdorff, L. The emergence of China as a leading nation in science. Research Policy, 35, 83-104, 2008.

[14] Glanzel, W. Seven myths in bibliometrics. About facts and fiction in quantitative science studies. In $\mathrm{H}$. Kretschmer, \& F. Havemann (Eds.), Proceedings of WIS 2008, Fourth International Conference on Webometrics, Informetrics and Scientometrics \& Ninth COLLNET Meeting, Berlin: Humboldt University, 2008.

[15] Trumbach, C., Payne, D. Identifying synonymous concepts in preparation for technology mining. Journal of Information Science, 33(6), 660-677.2007.

[16] Kataoka, K., Harada, A., Nagasaki, Y., Block copolymer micelles for drug delivery: design, characterization and biological significance. Advanced Drug Delivery Reviews. 47(1):113-131, 2001.

[17] Robinson, D.K.R., Huang, L., Guo, Y., and Porter, A.L. Forecasting Innovation Pathways for New and Emerging Science \& Technologies, Technological Forecasting \& Social Change, 80 (2), 267-285, 2013.

[18] Porter, A.L., Y. Guo, L. Huang, and D.K.R. Robinson (2010), Forecasting Innovation Pathways: The Case of Nano-enhanced Solar Cells, ITICTI - International Conference on Technological Innovation and Competitive Technical Intelligence Proceedings, Beijing.

\section{APPENDIX}

Table 1 Nano-enabled Drug Delivery: related terms

\begin{tabular}{l|ll|llll}
\hline No. & Category & Keywords & & & \\
\hline 1 & B & (biological & (bioavailab*or & biodistrib* & or biocompatib* & or \\
& & & cytotox & or
\end{tabular}




\begin{tabular}{|c|c|c|}
\hline & processes) & biodegradab*) \\
\hline 2 & I (imaging) & Image* or imaging \\
\hline 3 & $\mathrm{~T}$ (target) & (Cancer or tumor* or tumour* or "RNA interference" or RNAi) \\
\hline 4 & $\mathrm{H}$ (helpers) & $\begin{array}{l}\text { "polyethylene glycol" or pegylate or PEG or molecule* or } \\
\text { polymer* or polyethyleneimine or PEI or polyspermine or } \\
\text { polyproplyenimine or "poly lactic-co-glycolic acid" or PLGA or } \\
\text { cyclodextrin or dendrimer* or chitosan* or atelocollagen* or } \\
\text { "hyaluronic acid" or polypeptid* or peptid* or lipid* or ligand* or } \\
\text { HPMA or "Hydrolyzed Polymaleic Anhydride" or Micelle* or } \\
\text { Liposom* or conjugat* or Viral* OR Virus* or nonvira* or } \\
\text { non-vira*) }\end{array}$ \\
\hline 5 & $\mathrm{P}($ pharmaceutical $)$ & $\begin{array}{l}\text { (1) (agent* or Drug* or pharmac* or formulation*) } \\
\text { (2) (siRNA or "short interfering RNA") } \\
\text { (3) microRNA } \\
\text { (4) DNA or gene } \\
\text { (5) (Dox or Doxorubicin*) } \\
\text { (6) actives or adjuvant }\end{array}$ \\
\hline 6 & $\begin{array}{l}\text { D(delivery } \\
\text { approach) }\end{array}$ & $\begin{array}{l}\text { (1) (deliver* or vehicle* or carrier* or vector*) } \\
\text { (2) (treat* or therap*) } \\
\text { (3)(“control* releas*" or transduct* or transfect* or transport* or } \\
\text { translocat*) }\end{array}$ \\
\hline 7 & $\begin{array}{l}\mathrm{N}(\text { nano-delivery } \\
\text { vehicle) }\end{array}$ & $\begin{array}{l}\text { This category means GT nano Database or some approximation of } \\
\text { its search terms; also consider viral or virus or dendrimer or } \\
\text { colloid }\end{array}$ \\
\hline
\end{tabular}

Note: we focus on pharmaceutical/cargo $(\mathrm{P})$, nano-delivery-vehicle $(\mathrm{N})$, characteristics of the delivery approach (D), and the target for the drug cargo (T). As for B(biological processes), I(imaging) and $\mathrm{H}$ (helpers) categories, since these terms are more complex in terms of searching and for what they reveal about NEDD itself, we set them aside for the time being. 
Table 2 Increasingly Popular NEDD Research Topics for US and China

\begin{tabular}{l|r|r|r}
\hline US & A: & B: & \\
& number & of & number \\
of pre & Ratio: \\
A/B \\
& on & 2011 & \\
\hline siRNA delivery & 166 & 102 & 1.63 \\
Lipid nanoparticles & 24 & 16 & 1.50 \\
RAFT polymerization & 24 & 18 & 1.33 \\
photosensitizers & 20 & 16 & 1.25 \\
curcumin & 28 & 23 & 1.22 \\
silver nanoparticles & 49 & 41 & 1.20 \\
Nanoemulsion & 27 & 29 & 0.93 \\
alginate & 19 & 21 & 0.90 \\
Mesoporous silica & 40 & 45 & 0.89 \\
nanoparticles & 46 & 54 & 0.85 \\
PLGA nanoparticles & 93 & 110 & 0.85 \\
Nanocarriers & 20 & 24 & 0.83 \\
radical polymerization & 225 & 278 & 0.81 \\
Gold nanoparticles & 26 & 33 & 0.79 \\
Hydroxyapatite & 135 & 175 & 0.77 \\
iron-oxide & 45 & 59 & 0.76 \\
nanoparticles & 83 & 110 & 0.75 \\
Optical-properties & 6 & 8 & 0.75 \\
polymeric & 53 & 71 & 0.75 \\
nanoparticles & 39 & 0.74 \\
mucoadhesion & & & \\
Silica nanoparticles & & \\
Metal nanoparticles & & \\
\hline
\end{tabular}

\begin{tabular}{|c|c|c|c|}
\hline \multicolumn{4}{|l|}{ China } \\
\hline & $\begin{array}{r}\text { A: } \\
\text { number } \\
\text { of } \\
2011 \\
\text { on }\end{array}$ & $\begin{array}{r}\text { B: } \\
\text { number } \\
\text { of pre } \\
2011\end{array}$ & $\begin{array}{r}\text { Ratio: } \\
\text { A/B }\end{array}$ \\
\hline $\begin{array}{l}\text { Mesoporous silica } \\
\text { nanoparticles }\end{array}$ & 68 & 11 & 6.18 \\
\hline cell-penetrating peptides & 32 & 8 & 4.00 \\
\hline siRNA delivery & 108 & 29 & 3.72 \\
\hline cyclophosphamide & 7 & 2 & 3.50 \\
\hline curcumin & 22 & 9 & 2.44 \\
\hline resonance energy-transfer & 24 & 10 & 2.40 \\
\hline Non-Hodgkins-lymphoma & 7 & 3 & 2.33 \\
\hline signaling pathway & 35 & 16 & 2.19 \\
\hline targeted delivery & 64 & 30 & 2.13 \\
\hline Glioblastoma & 21 & 10 & 2.10 \\
\hline In-vivo evaluation & 27 & 13 & 2.08 \\
\hline Cell lung-cancer & 37 & 18 & 2.06 \\
\hline Magnetic-resonance & 22 & 11 & 2.00 \\
\hline photosensitizers & 26 & 13 & 2.00 \\
\hline $\begin{array}{l}\text { magnetic resonance } \\
\text { imaging }\end{array}$ & 51 & 26 & 1.96 \\
\hline Living cells & 68 & 35 & 1.94 \\
\hline in-vitro evaluation & 25 & 13 & 1.92 \\
\hline glioma & 42 & 22 & 1.91 \\
\hline PROTEIN-KINASE & 15 & 8 & 1.88 \\
\hline MRI & 46 & 25 & 1.84 \\
\hline
\end{tabular}


Table 3 Top WOSC and Cited WOSCs for the US and China

\begin{tabular}{|c|c|c|c|c|c|c|c|}
\hline Cited WOSC's & & & & WOSC & & & \\
\hline \multirow[t]{2}{*}{ number of Records } & 20807 & 10110 & & number of Records & 20807 & 10110 & \\
\hline & USA & China & & & USA & China & \\
\hline $\begin{array}{l}\text { BIOCHEMISTRY \& MOLECULAR } \\
\text { BIOLOGY }\end{array}$ & 17408 & 8047 & 2.16 & Pharmacology \& Pharmacy & 2848 & 1580 & 1.80 \\
\hline PHARMACOLOGY \& PHARMACY & 14258 & 8052 & 1.77 & Chemistry, Multidisciplinary & 3439 & 1797 & 1.91 \\
\hline MULTIDISCIPLINARY SCIENCES & 16374 & 6513 & 2.51 & Materials Science, Multidisciplinary & 2222 & 1738 & 1.28 \\
\hline CHEMISTRY, MULTIDISCIPLINARY & 11250 & 7668 & 1.47 & Biochemistry \& Molecular Biology & 2689 & 924 & 2.91 \\
\hline $\begin{array}{l}\text { BIOTECHNOLOGY \& APPLIED } \\
\text { MICROBIOLOGY }\end{array}$ & 13448 & 5216 & 2.58 & Chemistry, Physical & 1758 & 1435 & 1.23 \\
\hline CELL BIOLOGY & 13627 & 4393 & 3.10 & Nanoscience \& Nanotechnology & 2027 & 1350 & 1.50 \\
\hline $\begin{array}{l}\text { MEDICINE, RESEARCH \& } \\
\text { EXPERIMENTAL }\end{array}$ & 12101 & 3901 & 3.10 & Biotechnology \& Applied Microbiology & 2423 & 403 & 6.01 \\
\hline ONCOLOGY & 11596 & 4511 & 2.57 & Medicine, Research \& Experimental & 2374 & 453 & 5.24 \\
\hline BIOPHYSICS & 9977 & 4598 & 2.17 & Polymer Science* & 1013 & 1445 & 0.70 \\
\hline CHEMISTRY, PHYSICAL & 7763 & 6056 & 1.28 & Oncology & 2009 & 626 & 3.21 \\
\hline BIOCHEMICAL RESEARCH METHODS & 9759 & 4120 & 2.37 & Genetics \& Heredity & 1779 & 167 & 10.65 \\
\hline GENETICS \& HEREDITY & 10520 & 3220 & 3.27 & Materials Science, Biomaterials* & 923 & 947 & 0.97 \\
\hline $\begin{array}{l}\text { MATERIALS SCIENCE, } \\
\text { MULTIDISCIPLINARY }\end{array}$ & 7309 & 5384 & 1.36 & Engineering, Biomedical & 984 & 738 & 1.33 \\
\hline
\end{tabular}




\begin{tabular}{l|r|r|ll|r|r|r} 
ENGINEERING, BIOMEDICAL & 6790 & 4959 & 1.37 & Physics, Applied & 954 & 722 & 1.32 \\
MATERIALS SCIENCE, BIOMATERIALS & 6122 & 5150 & 1.19 & Cell Biology & 1050 & 286 & 3.67 \\
MEDICAL LABORATORY TECHNOLOGY & 6379 & 3425 & 1.86 & Chemistry, Organic & 588 & 355 & 1.66 \\
POLYMER SCIENCE & 5448 & 4672 & 1.17 & Physics, Condensed Matter & 644 & 392 & 1.64 \\
NANOSCIENCE \& NANOTECHNOLOGY & 6435 & 4470 & 1.44 & Virology & 887 & 114 & 7.78 \\
CHEMISTRY, ORGANIC & 6182 & 4180 & 1.48 & Biophysics & 421 & 390 & 1.08 \\
CHEMISTRY, MEDICINAL & 5422 & 3038 & 1.78 & Biochemical Research Methods & 672 & 153 & 4.39 \\
\hline
\end{tabular}




\begin{tabular}{l|r|r|r|r|r}
\hline & US & CHINA & $\begin{array}{l}\text { Ratio: } \\
\text { US/China }\end{array}$ & US-IC & China-IC \\
\hline Biochemical Research Methods & 672 & 153 & 4.39 & 0.22 & 0.35 \\
Biochemistry \& Molecular Biology & 2689 & 924 & 2.91 & 0.26 & 0.25 \\
Biophysics & 421 & 390 & 1.08 & 0.27 & 0.17 \\
Biotechnology \& Applied Microbiology & 2423 & 403 & 6.01 & 0.25 & 0.35 \\
Cell Biology & 1050 & 286 & 3.67 & 0.28 & 0.28 \\
Chemistry, Multidisciplinary & 3439 & 1797 & 1.91 & 0.26 & 0.22 \\
Chemistry, Organic & 588 & 355 & 1.66 & 0.23 & 0.21 \\
Chemistry, Physical & 1758 & 1435 & 1.23 & 0.29 & 0.24 \\
Engineering, Biomedical & 984 & 738 & 1.33 & 0.28 & 0.23 \\
Genetics \& Heredity & 1779 & 167 & 10.65 & 0.27 & 0.43 \\
Materials Science, Biomaterials & 923 & 947 & 0.97 & 0.32 & 0.21 \\
Materials Science, Multidisciplinary & 2222 & 1738 & 1.28 & 0.30 & 0.23 \\
Medicine, Research \& Experimental & 2374 & 453 & 5.24 & 0.25 & 0.29 \\
Nanoscience \& Nanotechnology & 2027 & 1350 & 1.50 & 0.30 & 0.25 \\
Oncology & 2009 & 626 & 3.21 & 0.28 & 0.23 \\
Pharmacology \& Pharmacy & 2848 & 1580 & 1.80 & 0.28 & 0.20 \\
Physics, Applied & 954 & 722 & 1.32 & 0.32 & 0.23 \\
Physics, Condensed Matter & 644 & 392 & 1.64 & 0.31 & 0.24 \\
Polymer Science & 1013 & 1445 & 0.70 & 0.28 & 0.16 \\
Virology & 887 & 114 & 7.78 & 0.23 & 0.29 \\
\hline
\end{tabular}


Table 5 Journal Comparison for the US and China

\begin{tabular}{l|r|r|r|r|r|r|r}
\hline & \multicolumn{3}{|l|}{ China } & \multicolumn{2}{l}{ US } \\
\hline Journal & $\begin{array}{l}\text { number } \\
\text { of } \\
\text { records }\end{array}$ & total & $\begin{array}{l}\text { world } \\
\text { share }\end{array}$ & $\begin{array}{l}\text { international } \\
\text { cooperation } \\
\text { share }\end{array}$ & total & $\begin{array}{l}\text { world } \\
\text { share }\end{array}$ & $\begin{array}{l}\text { international } \\
\text { cooperation } \\
\text { share }\end{array}$ \\
\hline Biomacromolecules & 689 & 125 & $\mathbf{0 . 1 8}$ & 0.26 & 576 & $\mathbf{0 . 8 4}$ & 0.25 \\
Biomaterials & 1416 & 377 & 0.27 & 0.25 & 451 & 0.32 & 0.35 \\
Gene Ther & 670 & 30 & $\mathbf{0 . 0 4}$ & 0.33 & 442 & $\mathbf{0 . 6 6}$ & 0.30 \\
Int. J. Nanomed & 628 & 236 & 0.38 & 0.16 & 442 & 0.70 & 0.34 \\
Int. J. Pharm & 1447 & 284 & 0.20 & 0.18 & 357 & 0.25 & 0.30 \\
J. Control. Release & 1465 & 177 & 0.12 & 0.28 & 322 & 0.22 & 0.36 \\
J. Mater. Chem & 616 & 249 & 0.40 & 0.20 & 243 & 0.39 & 0.38 \\
J. Virol & 661 & 13 & 0.02 & $\mathbf{0 . 4 2}$ & 231 & 0.35 & $\mathbf{0 . 1 9}$ \\
Langmuir & 972 & 142 & 0.15 & 0.22 & 122 & 0.13 & 0.20 \\
Mol. Ther & 839 & 19 & 0.02 & $\mathbf{0 . 6 3}$ & 89 & 0.11 & 0.21 \\
\hline
\end{tabular}


Table 6 Top 15 assignees in NEDD Derwent Patent

\begin{tabular}{|c|c|c|c|c|c|}
\hline Assignee & DII Code & Records & $\begin{array}{l}\text { Co-assi } \\
\text { gnee } \\
\text { patents }\end{array}$ & Country & Type \\
\hline TAKEDA PHARM CO LTD & TAKE & 125 & 13 & JP & $\mathrm{C}$ \\
\hline $\begin{array}{l}\text { MONSANTO TECHNOLOGY } \\
\text { LLC }\end{array}$ & MONS & 124 & 114 & US & $\mathrm{C}$ \\
\hline UNIV CALIFORNIA & REGC & 118 & 22 & US & A \\
\hline STINE SEED FARM INC & STIN-N & 109 & 109 & US & $\mathrm{C}$ \\
\hline INCYTE GENOMICS INC & INYT & 106 & 0 & US & $\mathrm{C}$ \\
\hline $\begin{array}{l}\text { US DEPT HEALTH\&HUMAN } \\
\text { SERVICES }\end{array}$ & USSH & 95 & 37 & US & G \\
\hline SMITHKLINE BEECHAM CORP & SMIK & 88 & 17 & UK & $\mathrm{C}$ \\
\hline BRISTOL-MYERS SQUIBB CO & BRIM & 74 & 14 & US & $\mathrm{C}$ \\
\hline CNRS CENT NAT RECH SCI & CNRS & 73 & 54 & FR & A \\
\hline BAYER AG & FARB & 67 & 13 & $\mathrm{DE}$ & $\mathrm{C}$ \\
\hline HUMAN GENOME SCI INC & HGSI & 65 & 3 & US & $\mathrm{C}$ \\
\hline $\begin{array}{l}\text { BIOWINDOW GENE DEV INC } \\
\text { SHANGHAI } \\
\text { NOVARTIS }\end{array}$ & BIOW-N & 64 & 64 & $\mathrm{CN}$ & $\mathrm{C}$ \\
\hline $\begin{array}{l}\text { VACCINES\&DIAGNOSTICS } \\
\text { INC }\end{array}$ & NOVS & 64 & 28 & $\mathrm{CH}$ & $\mathrm{C}$ \\
\hline AMGEN INC & AMGE & 60 & 5 & US & $\mathrm{C}$ \\
\hline $\begin{array}{l}\text { BODE GENE DEV CO LTD } \\
\text { SHANGHAI }\end{array}$ & BODE-N & 60 & 60 & $\mathrm{CN}$ & $\mathrm{C}$ \\
\hline
\end{tabular}

Notes: Country stands for where headquarter is.

For type, $\mathrm{C}$ is company, $\mathrm{A}$ is academic or research institute and $\mathrm{G}$ is government department. 
Figures

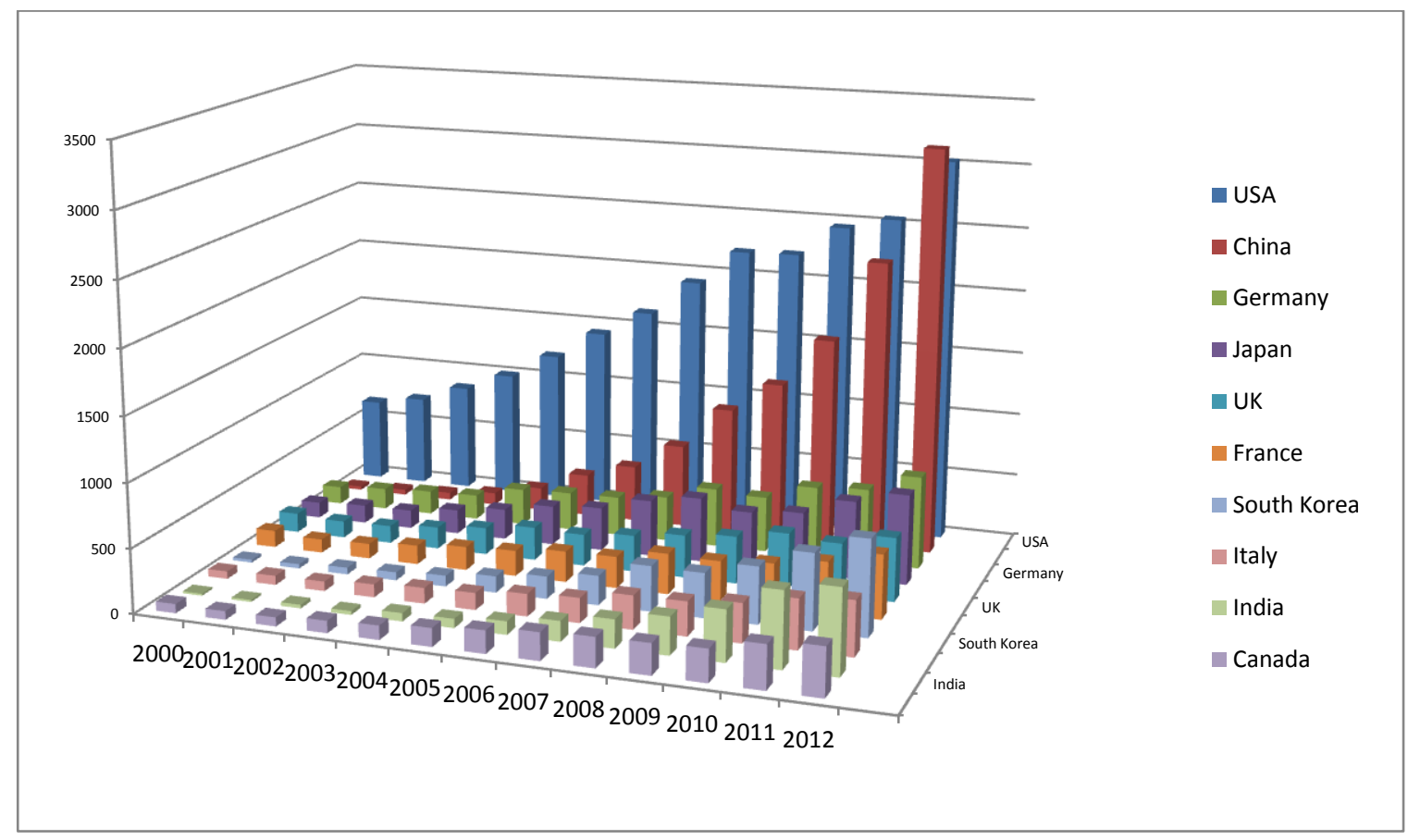

Figure 1 Activity Trends for the Top 10 NEDD Countries 


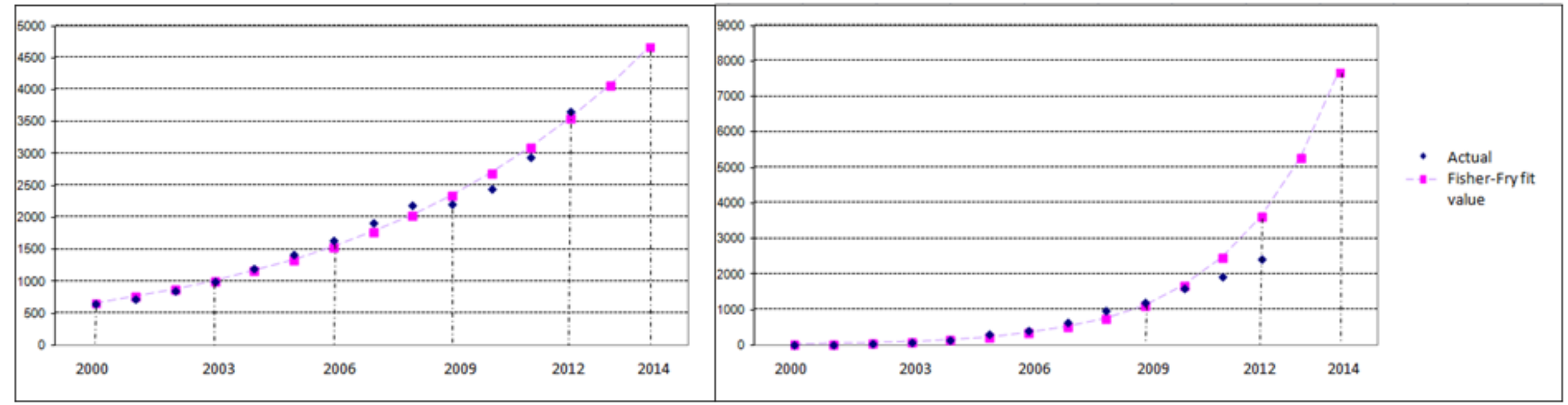

Figure 2 US (left)/ China(right) Cumulative Trend for NEDD-related Publications in WOS 


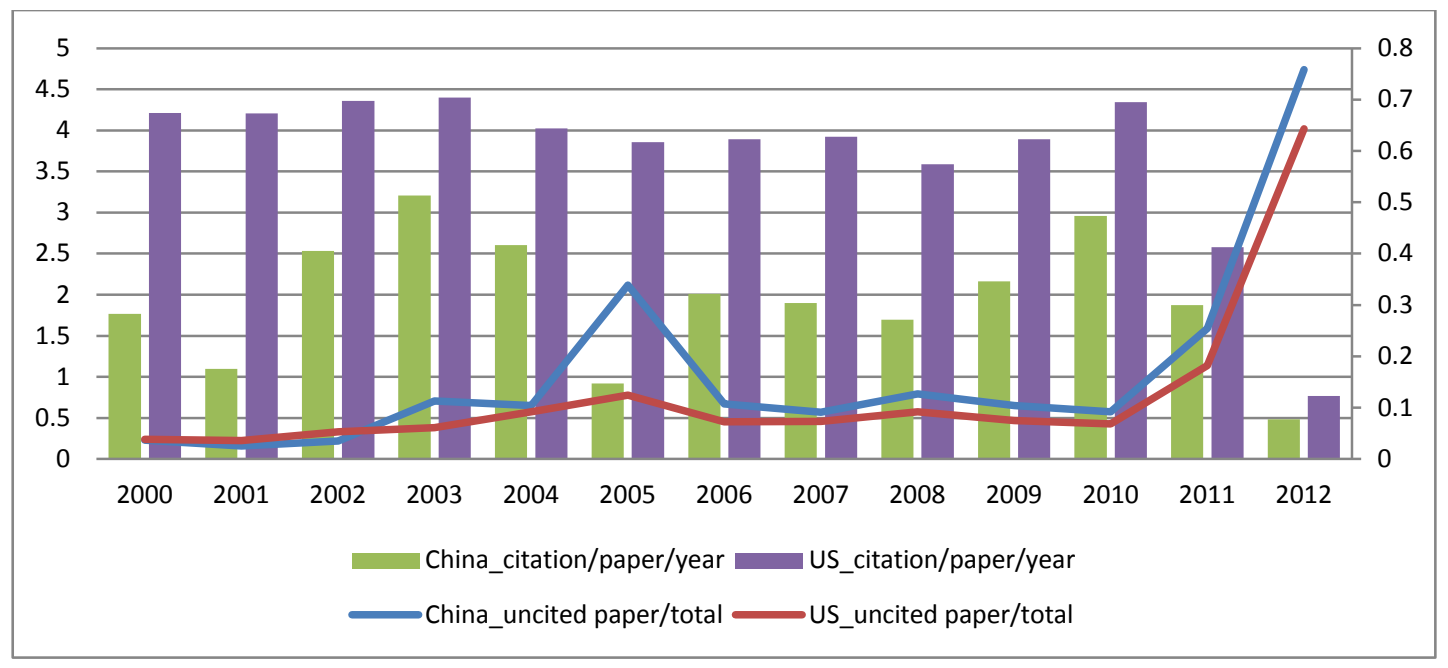

Figure 3 Citation trends for the US and China 


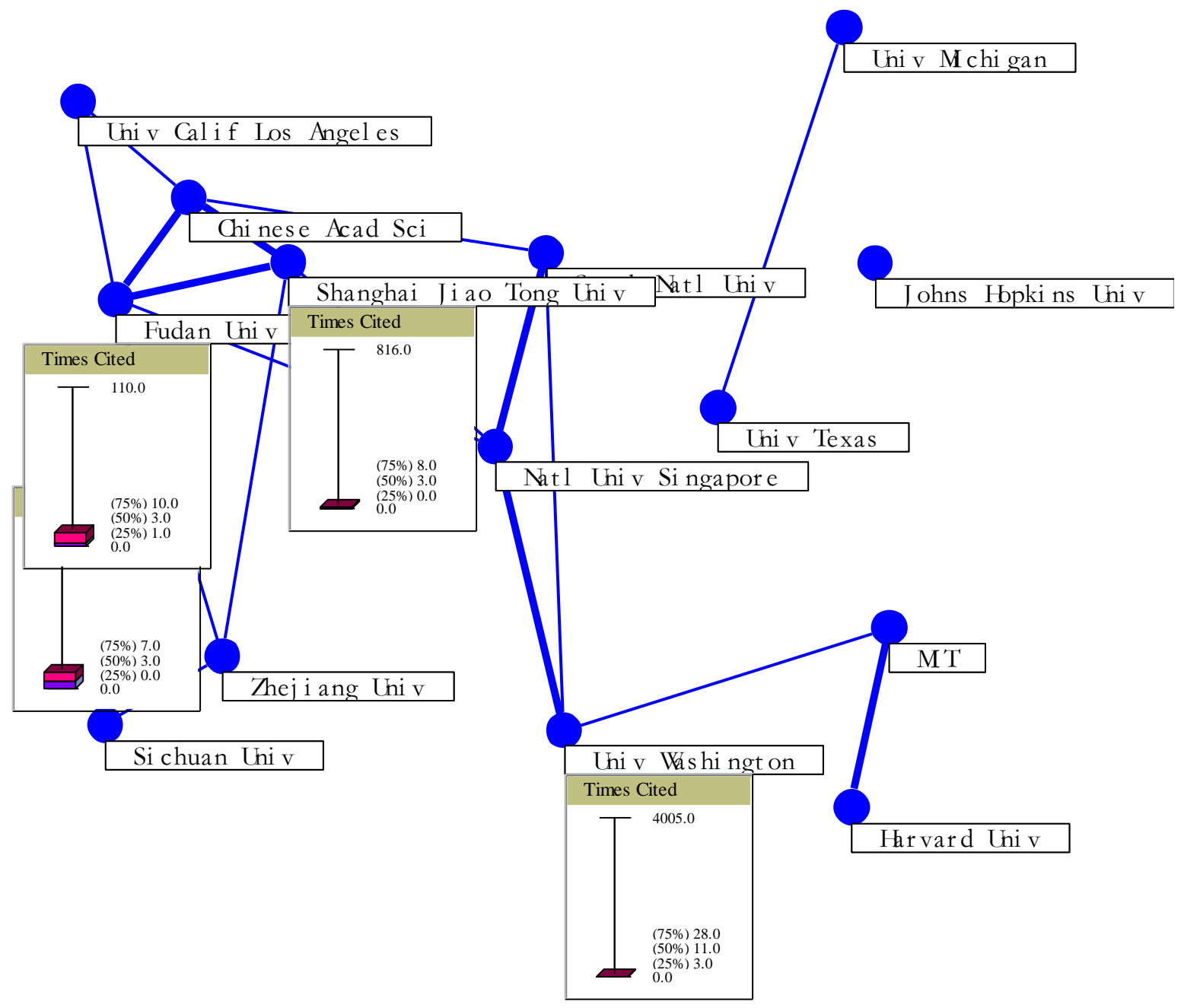

Uni v Tokyo
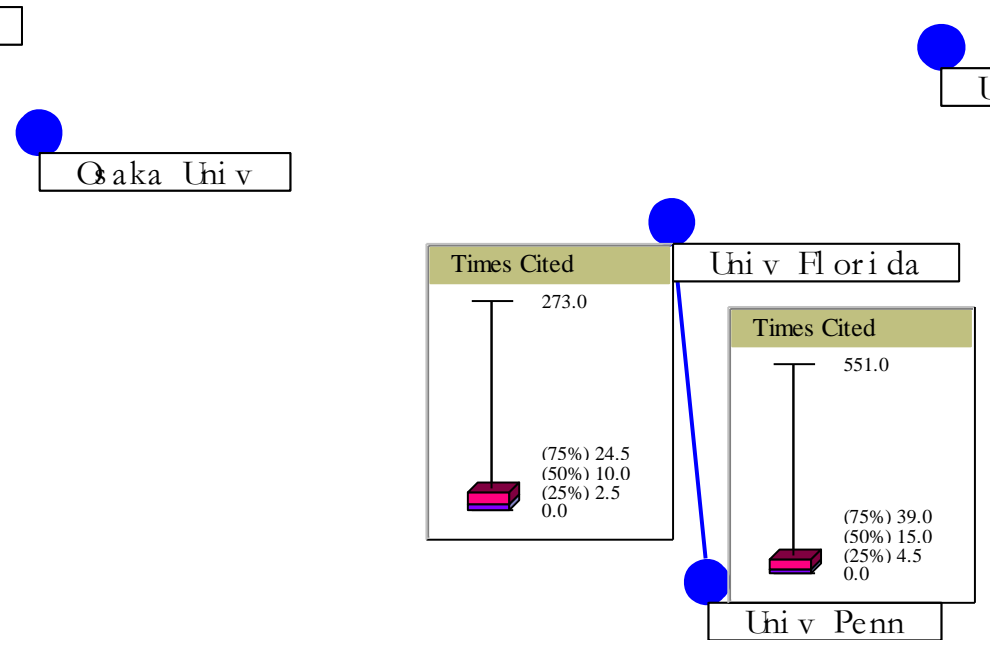

Figure 4 Top 20 affiliations (cross-correlation map based on top 200 cited reference) 


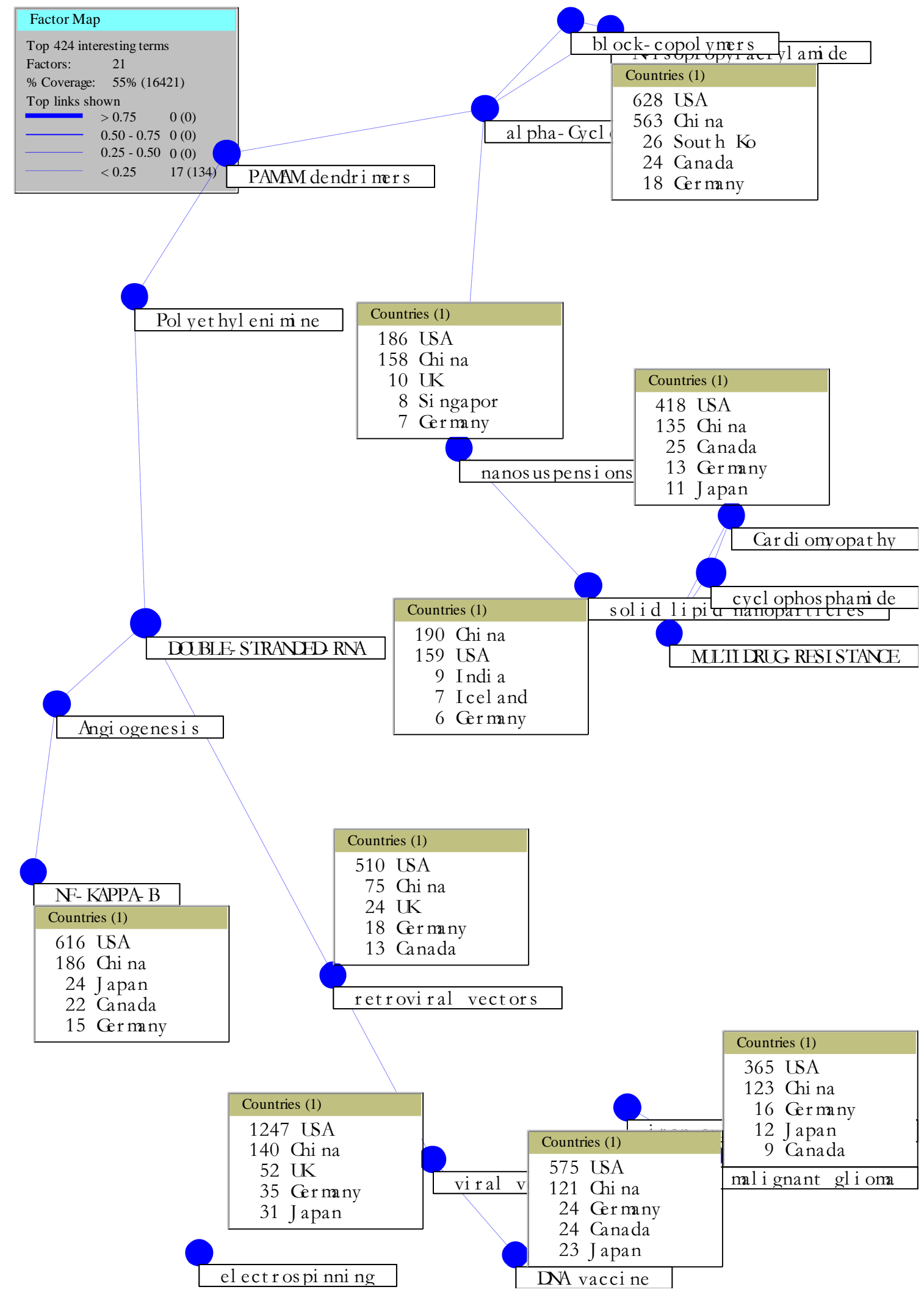

Figure 5 Factor map for US and China records 


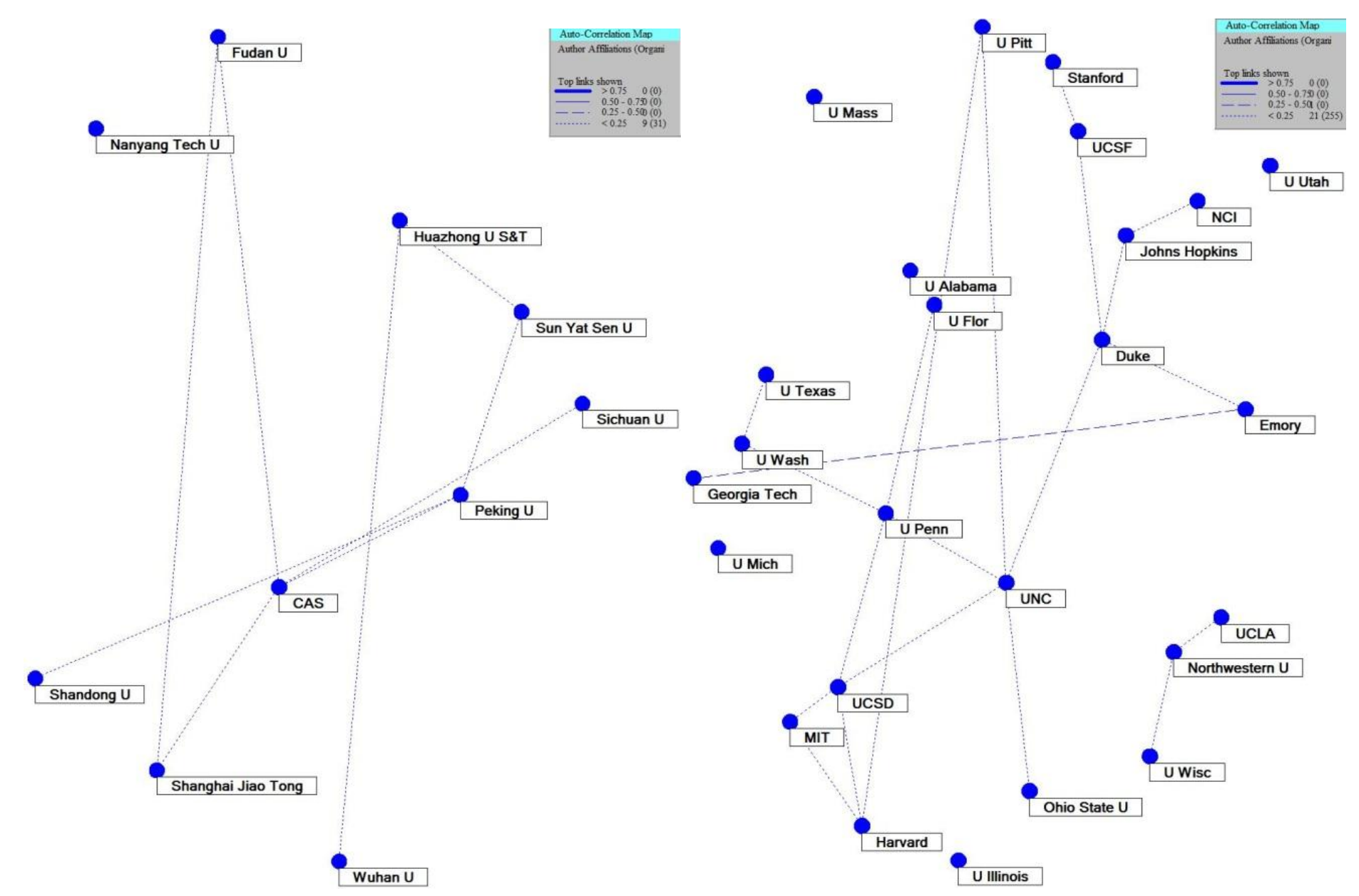

Figure 6a/b. Co-authorship Among the Leading Chinese Research Organizations (Left side) and Among US Organizations (Right side)

Note: These are MDS (Multi-Dimensional Scaling) representations (done in VantagePoint) in which location along the axes has no inherent meaning. Nodes closer together indicate likely relationship. However, such 2-dimensional representations must simplify complex relations among all the nodes, so are quite imperfect. We add a path-erasing algorithm to better indicate strength of relationships, shown by the strength of the connecting lines (see Legend). Absence of connecting lines indicates the relationship is below a threshold, not that it is zero. 


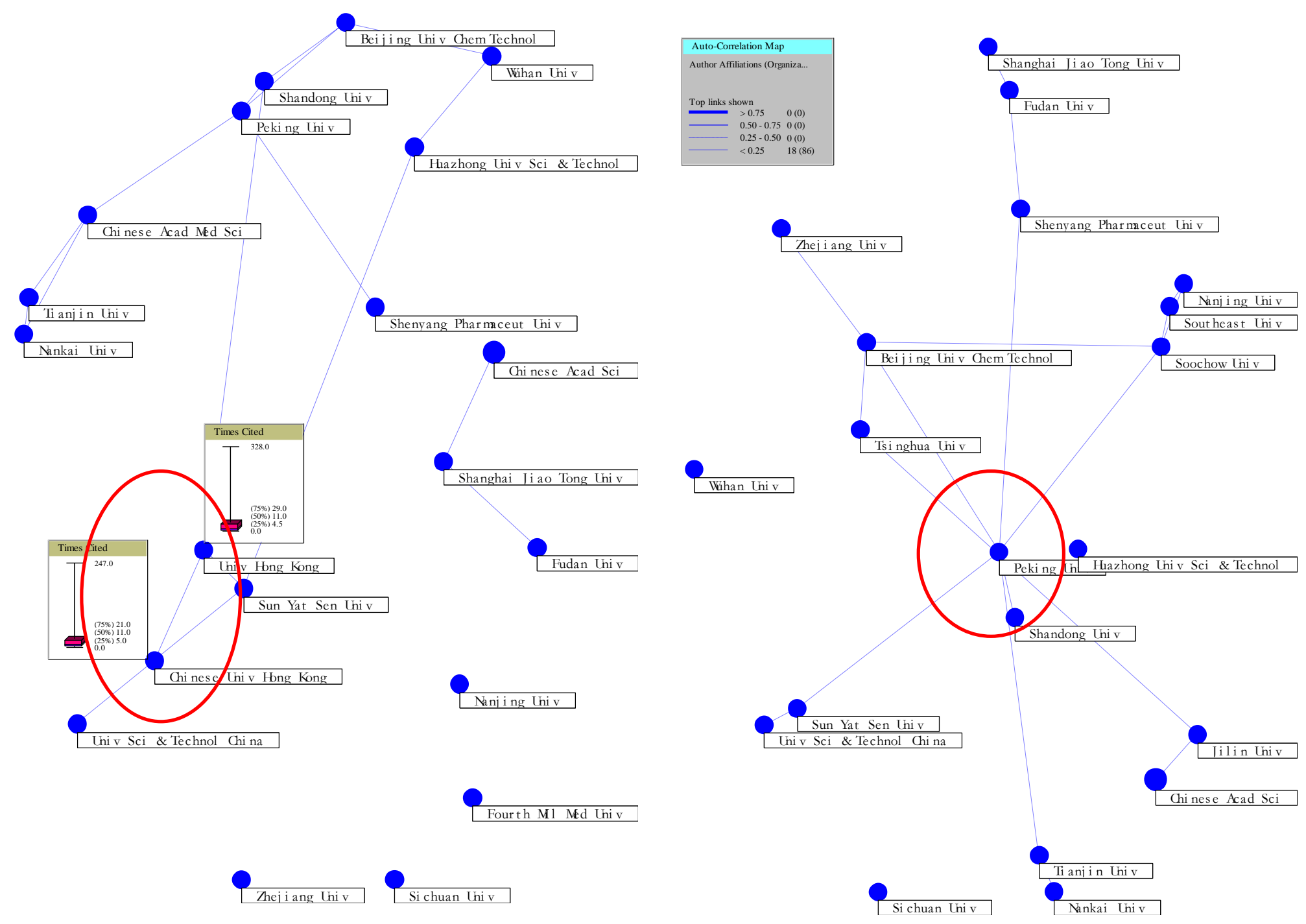

Figure 7 Top 20 affiliations for China (Left: pre-2011 (5723 records); right: 2011 and on (4387 records)) 